Preprint of the publication Delmelle, E.C. (2021). Transit-Induced Gentrification and

Displacement: The State of the Debate. In R. H. M. Pereira \& G. Boisjoly (Editors), Social Issues in Transport Planning (Advances in Transport Policy and Planning Vol. 8). Elsevier. https://doi.org/10.1016/bs.atpp.2021.06.005

\title{
Transit-Induced Gentrification and Displacement: The State of the Debate
}

Elizabeth C. Delmelle

Department of Geography \& Earth Sciences

University of North Carolina at Charlotte

Investments in new transportation infrastructure hold the potential to transform the urban socioeconomic landscape by reshaping accessibility and by encouraging new developments around these investments. This chapter outlines the theoretical arguments for why and how transport, specifically rail transit, is expected to impact the socioeconomic composition of neighborhoods and reviews the relevant empirical literature on the subject. Neighborhood socioeconomic change, including gentrification, can be viewed as the product of shifts in residential sorting of residents reacting to the placement of a new (transit) amenity which may place increased demand for living in a particular area. This demand may place an upward pressure on nearby housing values and rents, affecting the socioeconomic composition of those willing and able to afford these price premiums, thus spurring or accelerating gentrification. Rising land values may also lead to the disproportionate exit of lower-income residents unable to keep up with elevated rents or property taxes. To date, the empirical evidence on the link between transport investments and gentrification has mixed findings, very often underscoring the importance of local context in directing a neighborhood's path. Research has overwhelmingly centered on aggregate neighborhood changes, but several studies have recently emerged that center on individual movements that give rise to these neighborhood-scale outcomes.

Keywords: Transit; Gentrification; Neighborhood Change

Elizabeth C. Delmelle

Department of Geography and Earth Sciences

University of North Carolina at Charlotte 
Preprint of the publication Delmelle, E.C. (2021). Transit-Induced Gentrification and

Displacement: The State of the Debate. In R. H. M. Pereira \& G. Boisjoly (Editors), Social Issues in Transport Planning (Advances in Transport Policy and Planning Vol. 8). Elsevier. https://doi.org/10.1016/bs.atpp.2021.06.005

\section{Introduction}

Investments in transport often have multiple, sometime conflicting goals. For instance, new transport infrastructure offers mobility solutions to residents while also impacting land-use changes or encouraging or re-directing economic development. These goals may come into conflict when considering the impacts of transport, and in particular, new rail stations, on neighborhood outcomes. When new fixed rail stations are placed in lower-income neighborhoods, they may increase accessibility to opportunities that could lift the economic prospects of residents given that access has been directly linked to positive labor market outcomes (Andersson et al., 2017; Jin \& Paulsen, 2018). However, this increase in accessibility may increase demand for property nearby stations, placing an upward pressure on housing values and rents, potentially leading to the disproportionate exodus of those residents who could benefit the most from the mobility improvements. This transit-induced displacement and gentrification scenario has raised concerns from social equity advocates who contend that the economic development goals associated with transit, especially in the case of transit-oriented developments (TODs) - the intentional design considerations around fixed-rail transit stations that promote dense, mixed-use, walkable developments (Calthorpe, 1993) - have become a priority at the expense of vulnerable residents (Rayle, 2015; Revington, 2015).

Over the past several decades, cities across the United States have placed a renewed emphasis on investing in rail transit systems as a means for promoting urban redevelopment or city branding (Ferbrache \& Knowles, 2017). The impacts that these investments have had on the urban socioeconomic landscape and in potentially exacerbating gentrification, segregation, and inequalities, have generated a growing body of scholarly inquiry. In some instances, these concerns have led to protests of new transit plans as residents or advocacy groups have concluded that the potential negative impacts to neighborhoods outweigh the positives of transit expansion (Rayle, 2015). Contrary to the expected hypothesis, much of the empirical research on the subject has found the impacts of transit to be rather small, or at a minimum, challenging to quantify. In this chapter, I review the current state of knowledge on the topic, tracing the empirical and theoretical 
Preprint of the publication Delmelle, E.C. (2021). Transit-Induced Gentrification and

Displacement: The State of the Debate. In R. H. M. Pereira \& G. Boisjoly (Editors), Social Issues in Transport Planning (Advances in Transport Policy and Planning Vol. 8). Elsevier. https://doi.org/10.1016/bs.atpp.2021.06.005

links between transit's impact on land values, residential mobility, and neighborhood outcomes. Given the breadth of research on the topic, and heterogeneity across modes and geographic contexts (Efthymiou \& Antoniou 2013; Eliasson et al., 2020), I focus on fixed rail transit from a North American perspective. I close with future research directions at gaps in this state of knowledge.

\section{Theoretical Background}

The theoretical connection from investments in transport to neighborhood changes can be understood by tracing the impacts from land values to residential mobility decisions to neighborhood outcomes. Transport investments can alter nearby land values via two pathways: (1) it changes the accessibility landscape and (2) it provides new amenities near stations (especially in the case of TOD). In either case, these changes result in an increased demand for locations near transit stations, elevating property values and rents, which in turn impacts who moves into and out of a neighborhood. Those willing and able to pay a premium for transit proximity can outbid lowerincome residents who may be priced out of these locations. Furthermore, as a neighborhood's socioeconomic or demographic composition begins to change, some existing residents may also decide to relocate due to the changing fabric of the neighborhood. Even if lower-income residents are not disproportionately displaced, rising rents may reduce the overall supply of affordable housing in a metropolitan area and may therefore indirectly exacerbate inequalities in sorting patterns (Newman \& Wyly, 2006). In this respect, transit may serve to exclude lower-income residents from moving in to the newly invested-in neighborhood.

The first pathway to neighborhood change describes traditional urban location theory's connection between transportation and land use where accessibility plays a key role. According to this well-documented theory, as a result of the increased accessibility brought about by a new transport investment, transportation costs decline closer to the new infrastructure, resulting in a shift in demand, leading to increased land values (Huang, 1996). Per this perspective, households make a tradeoff between commuting costs and larger lot and home sizes; those with higher incomes are expected to pay higher transportation costs while opting to reside in larger, suburban homes on 
Preprint of the publication Delmelle, E.C. (2021). Transit-Induced Gentrification and

Displacement: The State of the Debate. In R. H. M. Pereira \& G. Boisjoly (Editors), Social Issues in Transport Planning (Advances in Transport Policy and Planning Vol. 8). Elsevier. https://doi.org/10.1016/bs.atpp.2021.06.005

the outskirts of cities (Alonso, 1964; Muth, 1969). In the case of urban rail transit investments, the accessibility improvements are usually marginal at the regional level, given that there is already an existing automotive infrastructure network. Accessibility improvements may be felt more acutely by those without automobile access or the ability to drive, in regions with higher levels of traffic congestion, and with larger and more well-connected the transit system. Overall, the impacts on development are thought to be more redistributive, directing growth that would have likely occurred already towards new stations where accessibility improvements are greatest (Cervero et al., 2002; Huang, 1996).

The second pathway to change is based on the increasingly important role that urban amenities are thought to play in influencing where residents choose to live, or sorting patterns, as many US cities are in the process of undergoing a reversal in the center-city poor/suburban-rich dichotomy that traditional urban location theory describes. Over the past several decades, younger, more educated, and higher-income residents have increasingly re-populated urban centers. Creative-cultural amenities that establish vibrant neighborhoods are attributed with helping to attract this population back to cities (Bereitschaft, 2014; Culver, 2017). Rail transit stations and their associated developments and design principles can be viewed as one such amenity (Bartholomew \& Ewing, 2011; Culver, 2017). As acknowledged in a review by Bartholomew \& Ewing (2011), the amenity-based design elements of TOD alone play a crucial role in reshaping land markets independent of the accessibility benefits provided by the system. Higgins and Kanaroglou (2018) demonstrate that the combined bundle of accessibility and TOD amenities establish distinct submarkets surrounding stations that generate heterogenous effects along a transit line. While differing from urban economic sorting models centered on accessibility, this amenitybased perspective does align with the longstanding sorting process described by Tiebout (1956) where households make residential location choice decisions based on the availability of local public goods. Sorting outcomes are a byproduct of the willingness and ability of households to pay for these goods. In the context of transit, a new station and associated developments serve to shift the demand towards these new amenities. 
Preprint of the publication Delmelle, E.C. (2021). Transit-Induced Gentrification and

Displacement: The State of the Debate. In R. H. M. Pereira \& G. Boisjoly (Editors), Social Issues in Transport Planning (Advances in Transport Policy and Planning Vol. 8). Elsevier. https://doi.org/10.1016/bs.atpp.2021.06.005

Both the accessibility and amenity- based pathway from transit investment to neighborhood outcomes rest on neoclassical economic theories of urban land values and residential sorting. Revington (2015) argues that there is a place for Marxist theory in explaining transit's role in perpetuating gentrification. According to this perspective, within a Capitalist system, the capitalist class' objective is to preserve its domination over labor through a process of capital accumulation. Rather than viewing all residents as having uniform preferences and levels of agency, a typical critique of the underlying assumptions behind neoclassical economic models, in a Marxist perspective, households do not react uniformly to urban spatial changes. As capital investments in infrastructure alters the locational advantage landscape (by impacting the placement of transportation, housing, and employment), households with the monetary and educational resources to act most swiftly to these changes are most poised to reap their benefits, furthering their self-interests. Those without these resources are left with locations of disinvestment and at a locational disadvantage (Revington, 2015). Investments in the built environment may therefore serve to reinforce spatial inequalities and may open new markets for the re-entry of capital by the most advantaged class, resulting in gentrification (Rérat, 2018).

Regardless of the theoretical lens, both neoclassical and Marxist explanations provide a framework for understanding that new rail transit stations are expected to contribute to rising land values through increased accessibility, amenities, or both, and that these changes should then precipitate down to impact who is willing or able to move into out of a nearby neighborhood, thus perpetuating gentrification. Given these theoretical considerations, I now turn to the empirical evidence that has evaluated how transit has impacted housing values and rents, residential mobility, and location choices, and finally neighborhood changes.

\section{Housing Values \& Rents}

The body of literature that has investigated the impacts of new transit investments on property values and rents is vast and while some meta-analyses have drawn the conclusion that proximity to new stations generally leads to price premiums (Debrezion, Pels, \& Rietveld, 2007; Hamidi, Kittrell, \& Ewing, 2016), the broader consensus of this work is that impacts vary 
Preprint of the publication Delmelle, E.C. (2021). Transit-Induced Gentrification and

Displacement: The State of the Debate. In R. H. M. Pereira \& G. Boisjoly (Editors), Social Issues in Transport Planning (Advances in Transport Policy and Planning Vol. 8). Elsevier. https://doi.org/10.1016/bs.atpp.2021.06.005

significantly depending on several factors. First, the type of station and development around the station appear to be an important precursor in determining price premiums. Walk-and-ride and stations with stronger TOD design principles such as mixed land-uses and walkability appear to generate higher premiums than park-and-ride stations which in some cases lead to price declines (Atkinson-Palombo, 2010; Hamidi et al., 2016; Zhong \& Li, 2016). In the case of San Diego, Duncan (2011a) found price premiums to be strongest when paired with pedestrian-friendly environments while condominiums in auto-dominated landscapes sold at a discount. Digging further into disentangling the impacts of rail stations and the surrounding land use and street design, Duncan (2011b) concluded that price premiums were contingent upon the permissive zoning regulations that enabled TOD, but that this type of zoning had a negative impact on home values beyond the area immediately surrounding the stations.

Second, the initial characteristics of a neighborhood may determine whether property values increase. At least two studies suggested that larger capitalization effects were experienced in higher-income neighborhoods (Bowes \& Ihlanfeldt, 2001; D. B. Hess \& Almeida, 2007). However, Mathur (2020) found positive price impacts across the entire spectrum of properties in the case of the San Francisco BART heavy rail system. Redfearn (2009) makes an important point with respect to modeling efforts that attempt to capture price premiums and fail to recognize the significant variations across time and neighborhood types. In the case of light rail in Los Angeles, Redfearn (2009) shows that a global model yielded significant omitted variable biases, producing a wide range of coefficients. However, when a local regression was used, a more stable set of estimates was produced, all pointing to no impact of transit on local house prices. The differences in these two studies may stem from differences in metropolitan-level factors or in the type of rail system under investigation (light versus heavy) or due to different modeling approaches (global versus local).

Distance from a station is another factor with varying and sometimes contradictory evidence. Some studies have suggested that properties closest to a station will experience negative externalities such as noise and therefore undergo price declines (Golub, Guhathakurta, \& 
Preprint of the publication Delmelle, E.C. (2021). Transit-Induced Gentrification and

Displacement: The State of the Debate. In R. H. M. Pereira \& G. Boisjoly (Editors), Social Issues in Transport Planning (Advances in Transport Policy and Planning Vol. 8). Elsevier. https://doi.org/10.1016/bs.atpp.2021.06.005

Sollapuram, 2012; Ke \& Gkritza, 2019). In the case of Atlanta, Bowes and Ihlanfeldt (2001) found negative home value impacts for higher-income neighborhoods located close to downtown and within one quarter mile of a station. The largest, positive impacts were found one quarter to one half mile of a station, away from the central business district. The authors attributed these benefits primarily to the presence of retail clusters near stations that appear to be valued by homeowners, supporting the amenity draw argument of TOD. Negative impacts were also found for properties in lower-income neighborhoods beyond a quarter of a mile from a station in the case of Atlanta.

The timing of price premium effects is another factor that can cause variations across studies. Many of the earlier studies on the transit-home value connection were cross-sectional in nature which prohibited an in-depth examination onto when capitalization effects may begin and end. A more recent study by Pilgram and West (2018) for the case of a new transit line in Minneapolis, MN used repeat sales data found for single family homes, price premiums were present only in the years immediately following the opening of the line and dissipated to zero seven years after service began. The authors controlled for station heterogeneity and tested the robustness of their results on several sets of control groups - limitations present in earlier studies. An additional analysis on housing prices in Minneapolis showed single family home prices increasing following the announcement of the line, but then stabilizing once it actually opened (Cao \& Lou, 2017).

Finally, metropolitan-level factors are a likely determinant in property price premiums. Case studies in varying metropolitan areas have ranged from positive impacts of greater than 10\% in the case of condominiums in Charlotte, North Carolina (Billings, 2011) to negative impacts along the new light rail line in Norfolk, Virginia (Wagner, Komarek, \& Martin, 2017). Given the strong effects of TOD, as opposed to auto-dominated landscapes on generating price increases described above, the survey of nation-wide TOD projects by Hess \& Lombardi (2004) offers one explanation behind these metropolitan-level variations. According to their analysis, TODs that are successful at attracting new developments are in rapidly growing places with a strong local economy such as San Diego and absent from older cities like Buffalo or St. Louis. Within growing 
Preprint of the publication Delmelle, E.C. (2021). Transit-Induced Gentrification and

Displacement: The State of the Debate. In R. H. M. Pereira \& G. Boisjoly (Editors), Social Issues in Transport Planning (Advances in Transport Policy and Planning Vol. 8). Elsevier. https://doi.org/10.1016/bs.atpp.2021.06.005

cities, the most successful stations are then found outside of struggling neighborhoods (Hess and Lombardi, 2004). This aligns with the notion that transit redirects growth towards stations rather than generates it and so, there must be growth to direct (Cervero et al., 2002).

Many of these empirical findings are consistent with the preconditions for station-area development to occur stipulated by Huang (1996). These include a healthy and growing metropolitan economic climate - as discussed previously, in the case of rail investments, stations are more likely to guide developments towards them rather than generating a substantial amount of new growth. This is also the case with residential properties - with a growing population and healthy demand for housing, this demand may be redirected towards new or existing properties near stations, but absent of growth, it is unlikely to prompt enough existing residents to move within the metropolitan area near a station. In addition, there needs to be coordinate local government policies to enact zoning changes to enable higher density uses and there must be a willing residential base to accept these density changes or mixed land uses. This point was emphasized in the findings from (Duncan, 2011a, 2011b). Finally, there needs to be enough available land for developments to take place on. Areas that are already extensively built up are unlikely to experience drastically new developments as the costs of acquisition and demolition, for example, would be prohibitive.

\section{Residential Mobility}

Given that in some cases, the combined effects of accessibility and, perhaps, more importantly, associated TOD characteristics surrounding new rail stations do generate price premiums, shifts in sorting behaviors might be expected in those areas. The residential mobility impacts may include a change in those moving into new developments or an out-bidding of higherincome residents for existing properties. It might involve a change in those moving out as a reaction to higher rents or property taxes, or it might be some combination of both. Studies on residential mobility responses to transit have been rather limited, especially compared to those on property value effects or neighborhood outcomes. This is primarily due to an absence of a 
Preprint of the publication Delmelle, E.C. (2021). Transit-Induced Gentrification and

Displacement: The State of the Debate. In R. H. M. Pereira \& G. Boisjoly (Editors), Social Issues in Transport Planning (Advances in Transport Policy and Planning Vol. 8). Elsevier. https://doi.org/10.1016/bs.atpp.2021.06.005

convenient data sources to capture movements or displacement, a conundrum that has hindered the gentrification literature more broadly from quantifying displacement (Rayle, 2015).

Several studies have attempted to capture characteristics of those moving into new transit or TOD neighborhoods based on surveys. There is some evidence that those moving into TODs or near new stations are more likely to be younger or child-less couples, consistent with the creativecultural amenity theory discussed above (Cao \& Schoner, 2013; Cervero, 2007; Liu, Deng, \& Le Vine, 2016). However, the similarities across cities and studies seem to stop there. Some suggest that residents in TODs and near new stations have lower-incomes and are more likely to be Hispanic or Asian (Cervero, 2007; Liu et al., 2016) while others show the opposite: that they tend to have higher-incomes and are less likely to be Hispanic (Lund, 2006).

Studies employing residential mobility data in the context of transit stations are much scarcer. Two studies use the Panel Study on Income Dynamics (PSID), the longest running social survey of residents throughout the United States, to track movements out of new transit neighborhoods nationwide from 1970-2014 (Delmelle \& Nilsson, 2020; Nilsson \& Delmelle, 2020). The first study tests the displacement hypothesis, which posits that lower-income residents have disproportionately moved out in the time just before a station opened or just afterwards. The results showed that while lower-income residents were more likely to move overall, those in new transit neighborhoods were not significantly more likely to move, thus providing no supporting evidence at a national scale for the displacement hypothesis. This null finding was the case for renters and homebuyers, when differentiated by decade, and for varying definitions of what constituted a 'transit neighborhood' (Delmelle \& Nilsson, 2020). In a follow-up analysis, the authors examined the neighborhood relocation choices of those moving out of new transit neighborhoods - testing more generally the role of stations on metropolitan sorting patterns. In that analysis, there was some evidence of unequal sorting outcomes: of those moving out, middle and higher-income homeowners were more likely to move to a neighborhood of a higher income composition whereas lower-income homeowners and renters did not see an increased probability of neighborhood upgrading by income (Nilsson \& Delmelle, 2020). One hypothesis behind this 
Preprint of the publication Delmelle, E.C. (2021). Transit-Induced Gentrification and

Displacement: The State of the Debate. In R. H. M. Pereira \& G. Boisjoly (Editors), Social Issues in Transport Planning (Advances in Transport Policy and Planning Vol. 8). Elsevier. https://doi.org/10.1016/bs.atpp.2021.06.005

finding is that middle- and higher-income homeowners are better able to capitalize on the price premiums that transit placed on their properties. This would be consistent with the studies identifying greater price impacts in middle- and higher-income neighborhoods or with Marxists notions that those with greater resources can more quickly react and benefit from changes in the housing market.

National-scale studies such as the ones mentioned above capture very broad changes, or averages, but may mask local nuances where displacement may have occurred. Rodnyansky (2018) used a local dataset of tax records in Los Angeles to test the transit-induced displacement hypothesis and reached the same conclusion: that lower-income residents did not disproportionately leave transit neighborhoods. In fact, they were less likely to move. This finding does align with the null capitalization impacts reported by Redfearn (2009) in Los Angeles. Despite the lack of empirical support, however, narratives surrounding Los Angeles' transit system continue to suggest that it is responsible for gentrification and displacement within the city (Rosenthal, 2018).

The use of residential mobility data to measure displacement has received some criticism when applied in the broader gentrification literature - it was not designed for that purpose and reduces a complex process into a single data point in time. As an alternate, Delmelle et al. (2020) used eviction filing rates to test the transit-induced displacement hypothesis in a study of four US cities: Newark, New Jersey; San Diego, California; Seattle, Washington; and St. Louis, Missouri. Evictions represent a form of direct displacement, or an involuntary move, that occurs when a tenant is unable to afford rent increases, for instance. The use of eviction data to study displacement therefore has some theoretical advantages as compared to residential mobility data, but limitations remain. For example, not all evictions result in formal court filings, many are settled informally, and these are not captured in official statistics. In the case of rising rents, many renters will simply opt to relocate once their lease expires rather than going through an eviction process. Nonetheless, it represents an alternative vantage point from which to investigate the problem. According to the four-city study, Delmelle et al. (2020) compared eviction filing rates in gentrifiable neighborhoods 
Preprint of the publication Delmelle, E.C. (2021). Transit-Induced Gentrification and

Displacement: The State of the Debate. In R. H. M. Pereira \& G. Boisjoly (Editors), Social Issues in Transport Planning (Advances in Transport Policy and Planning Vol. 8). Elsevier. https://doi.org/10.1016/bs.atpp.2021.06.005

close to new rail stations with those in similar gentrifiable neighborhoods away from the stations in each city. No significant differences were found between the two suggesting that the new stations in these four contrasting cities did not lead to different eviction rates.

Overall, the limited studies that have attempted to capture transit's impact on residential sorting have provided very minimal support that it plays a significant role in reshaping sorting trends. However, more research is certainly needed in this area, especially those that emphasize the nuances that the house price capitalization has revealed - focusing on changes in the immediate vicinity of stations with strong TOD principles.

\section{Neighborhood Change}

The net result of changes in land and housing values, residential mobility, and location choices is a change to the aggregate characteristics of a neighborhood. While gentrification is typically the outcome under investigation in studies examining a link between transit and neighborhood change (Padeiro, Louro, \& da Costa, 2019), that is just one pathway in which a neighborhood's composition may change. Gentrification represents a particular type of change characterized by an influx of new, younger, highly educated with professional, highly paid jobs and mostly White population. This new population replaces an older, working-class, lowerincome, and minority population in neighborhoods close to the urban core that had undergone disinvestment and physical deterioration (Marcuse, 1985). Other types of neighborhood changes may include improvements or declines to the socioeconomic circumstances of existing residents (incumbent upgrading/downgrading), or other pathways that lead to a shift in the racial, socioeconomic, or housing characteristics composition of the neighborhoods (Delmelle, 2017).

The evidence pertaining to transit's impact on neighborhoods is very consistent with the variations revealed in the land/home value and residential mobility literature. As the number of studies on the topic has increased, it is increasingly evident that gentrification is not the typical outcome that follows the placement of a new station. Rather, in some circumstances, when the 
Preprint of the publication Delmelle, E.C. (2021). Transit-Induced Gentrification and

Displacement: The State of the Debate. In R. H. M. Pereira \& G. Boisjoly (Editors), Social Issues in Transport Planning (Advances in Transport Policy and Planning Vol. 8). Elsevier. https://doi.org/10.1016/bs.atpp.2021.06.005

existing pre-conditions are prime, transit may act as an accelerator to changes, but in many instances, does little to alter the trajectory of the neighborhood.

While many neighborhoods do not change in the time after a station is built, of those that do, there are some similarities in the ways in which they change. For instance, there is evidence that the share of college educated residents (Deka, 2017; Kahn, 2007; Nilsson \& Delmelle, 2018) and multifamily housing (Dong, 2017; Nilsson \& Delmelle, 2018) increased in Census tracts near stations. Consistent with the prior house value literature, changes have been found to occur more often in neighborhoods close to a walk-and-ride or TOD station and in faster growing metropolitan areas (Baker \& Lee, 2019; Nilsson \& Delmelle, 2018) - though there are some exceptions to this as well. Two studies examined changes around stations in Portland, Oregon, a city heralded for its progressive land-use policies, located in the fast-growing Western United States and neither found evidence that new stations led to an increase in gentrification-type chances or reduced affordability in nearby neighborhoods (Baker \& Lee, 2019; Dong, 2017). Dong (2017) found that densification and the share of rental units increased - this increased supply may serve to offset rising demand.

Two studies found that incomes and housing values or rents increased in new transit neighborhoods (Bardaka, Delgado, \& Florax, 2018; Pollack, Bluestone, \& Billingham, 2010), however, both of these analyses compared transit neighborhoods to the city or metro-area as a whole. Other research has pointed out that city-wide comparisons tend to inflate price capitalization impacts (Pilgram \& West, 2018). The use of a set of control neighborhoods that closely match the 'treatment' or transit neighborhoods is the more desirable method. The lack of inclusion of appropriate counterfactuals is one limitation of much of the neighborhood change research and has been attributed to some of the discrepancies in their findings (Padeiro et al., 2019). Echoing the price capitalization literature, Heilmann (2018) found neighborhood-level income changes to be contingent upon its initial income composition - strongest for the most well-off, and weakest or negative for poorer.

With respect to changes in the racial makeup of neighborhoods, a number of studies found it to be unchanged - even when other characteristics did change in a direction that pointed to 
Preprint of the publication Delmelle, E.C. (2021). Transit-Induced Gentrification and

Displacement: The State of the Debate. In R. H. M. Pereira \& G. Boisjoly (Editors), Social Issues in Transport Planning (Advances in Transport Policy and Planning Vol. 8). Elsevier. https://doi.org/10.1016/bs.atpp.2021.06.005

gentrification (Barton \& Gibbons, 2017; Deka, 2017; Nilsson \& Delmelle, 2018; Pollack et al., 2010) - this is an effect that has previously been identified in the neighborhood change literature and is not necessarily unique to transit neighborhoods (Delmelle, 2016). Of course, deviations from this null effect on racial changes exist. For instance, Hess (2018) reported on a rising share of Whites corresponding to the start of construction in neighborhoods in Seattle, but a growth in racial and ethnic diversity in more peripheral locations. Delmelle et al. (2020) used mortgage lending applications from the Home Mortgage Disclosure Act (HMDA) to examine changes in the income and racial composition of those applying for loans along a new transit corridor in Charlotte, North Carolina. By comparing lending rates over time between transit neighborhoods and a set of controls, the authors showed that there was a significant decline in the share of Black loan applicants in transit neighborhoods and an increase in White applicants following the announcement of the opening of the new line. They did not find a significant difference in the income profile of applicants. A further scrutiny of the data unveiled significant heterogeneity along the rail line with the most significant changes occurring in neighborhoods closest to the city center. A complementary analysis of property advertisement text illustrated that the light rail was advertised most often in neighborhoods closest to the core and in proximity to a previously gentrified neighborhood. Overall, the analysis helped to underscore the importance of the contextual circumstances that may shape changes in residential location decisions. Coupled with existing amenities serving to attract a younger and Whiter population - proximity to the urban core, walkability, the presence of breweries, and importantly, proximity to an established, gentrified neighborhood - the opening of the new rail line likely served to exacerbate the speed of changes in those neighborhoods. However, further from that core, in more suburban, and largely minority neighborhoods, changes were much less apparent.

\section{Discussion and Conclusions}

The current state of the literature increasingly suggests that the impacts of transit on neighborhoods is either marginal or very difficult to quantify. In the review of existing empirical studies beginning with transit's impact on land and property values, the evolution of this work 
Preprint of the publication Delmelle, E.C. (2021). Transit-Induced Gentrification and

Displacement: The State of the Debate. In R. H. M. Pereira \& G. Boisjoly (Editors), Social Issues in Transport Planning (Advances in Transport Policy and Planning Vol. 8). Elsevier. https://doi.org/10.1016/bs.atpp.2021.06.005

suggests that more sophisticated modeling efforts that correct for spatial heterogeneity, differentiate impacts between types of neighborhoods, and that utilize a proper set of controls, find more muted impacts than earlier research that did not do these things. If the impacts on housing values and rents is less than originally thought, then the subsequent negligible impacts on residential sorting and neighborhood change studies are not tremendously surprising. Collectively, this body of work suggests that changes associated with new stations are not automatic and are likely only when certain contextual circumstances accompany these stations. These include presence of other cultural amenities, strong TOD design principles around stations, and economically vibrant metropolitan climate. After more than two decades of empirical research, many of the findings reiterate the original stated preconditions for successful TOD (Hess \& Lombardi, 2004; Huang, 1996). Nonetheless, as reported in the recent article by Carlton (2019), many transit planners have unrealistic expectations on the development potential surrounding TOD, placing prospects above what would be expected given the current state of knowledge on the subject. Thus, many transit projects have likely been pushed through based on unachievable promises - and thus academics have continued to capture these null effects.

Limitations in the body of work that have investigated neighborhood outcomes stemming from transit investments remain. As reported in the review by Padeiro et al. (2019), many of the neighborhood-scale analyses fail to utilize a proper set of control neighborhoods to test whether trends differ from other similar neighborhoods in a metropolitan area. As the price capitalization literature has increasingly shown, this can have a significant impact on results and needs to become the norm in the neighborhood studies (Pilgram \& West, 2018). Likewise, controlling for heterogeneity and isolating transit from other confounding factors remains a challenge. Finally, the sensitivity of results to their spatial and temporal scales needs further scrutiny. Most neighborhood-scale studies use Census tracts which may be too large to capture changes that may only occur in the area immediately surrounding a station. Census data are also typically restricted to examining changes at a decennial time-frame, or use notoriously unreliable estimates in between. Recent price capitalization literature has suggested that price increases are felt only in the years immediately preceding and following a station opening (Cao \& Lou, 2017; Pilgram \& 
Preprint of the publication Delmelle, E.C. (2021). Transit-Induced Gentrification and

Displacement: The State of the Debate. In R. H. M. Pereira \& G. Boisjoly (Editors), Social Issues in Transport Planning (Advances in Transport Policy and Planning Vol. 8). Elsevier. https://doi.org/10.1016/bs.atpp.2021.06.005

West, 2018). It could be that the course temporal granularity of Census data does not enable changes to be capture. These limitations could be addressed by the use of alternate datasets.

Despite the limitations that exist in the state of the transit-induced gentrification literature, there are other plausible explanations for the lack of consistent evidence supporting the hypothesis. The first is the fact that many new rail lines are placed through previously underutilized industrial or commercially zoned land uses. Coordinating higher-density residential construction around stations increases the supply of housing and does not physically displace anyone in doing so. Many studies have agreed that a hallmark of changes around stations is an increase in density or multifamily housing (Bhattacharjee \& Goetz, 2016; Dong, 2017; Nilsson \& Delmelle, 2018) as it is one of the very essences of TOD principles. Some may argue that many of these new developments are higher-end luxury apartment units unaffordable to lower-income residents, and thus represent a form of exclusionary displacement (Rayle, 2015). This may certainly be the case in areas immediately surrounding a station, however, it is also relevant to acknowledge current debates on the role of increasing housing supply more generally on increasing overall affordability (Been, Ellen, \& O’Regan, 2019). As summarized nicely their recent review article, Been et al. (2019) suggest that building new market rate housing does provide a moderating effect on the affordability landscape for low- and moderate- income families, but that this is not a sufficient way of addressing housing affordability in a competitive market. Government intervention is likely necessary for increasing the supply of affordable housing. Coordinating these efforts in TODs would seem to be a prime opportunity to do so and the mechanisms for successfully achieving this is a welcome area of research.

A second potential explanation behind the null displacement findings surrounds the notion of locational affordability - that the transportation savings enabled by residing in highly accessible locations will offset higher housing costs (Renne, Tolford, Hamidi, \& Ewing, 2016). In this scenario, displacement may not occur given that residents experience a new cost savings on transportation even though rents may have risen. The literature is far from settled on whether residing close to transit provides enough residual income to overcome a rent premium. Two recent 
Preprint of the publication Delmelle, E.C. (2021). Transit-Induced Gentrification and

Displacement: The State of the Debate. In R. H. M. Pereira \& G. Boisjoly (Editors), Social Issues in Transport Planning (Advances in Transport Policy and Planning Vol. 8). Elsevier. https://doi.org/10.1016/bs.atpp.2021.06.005

studies offer to contrasting conclusions on the matter - Smart and Klein (2018) suggest that the cost savings provided by living in transit-rich neighborhoods in the United States have been overstated while Makarewicz et al. (2020) take a more granular approach and do find evidence of significant savings for several income groups, but not the lowest.

Finally, this review focused on quantitative analyses of neighborhood changes and an argument can be made that transit changes neighborhoods in ways that are unquantifiable removing or possibly improving their sense of place or community. The influx of newer residents to TOD locations, even if they do not displace residents in nearby neighborhoods, may change the cultural preferences and make established residents feel out of place (Hyra, 2015). There have been far fewer qualitative studies on the impacts of transit neighborhoods - though the few that exist do note that residents generally tend to view transit favorably (Jackson \& Buckman, 2020; Lung-Amam, Pendall, \& Knaap, 2019; Nilsson, Schuch, Delmelle, \& Canales, 2020), but that this sentiment is stronger for newer residents, as skepticism by poorer and minority residents remain regarding large public investments. Longer-term studies on the impacts felt by residents remains a welcome area of future research.

Literature debates surrounding transit-induced gentrification and displacement have followed broader public debates as fears about planned transit systems' impact on communities has caused resistance by residents (Rayle, 2014). This speaks to a broader need to reconcile investments in underserved communities and subsequent fears of gentrification - or a 'catch-22' (Danley \& Weaver, 2018). For historically marginalized communities, a sudden influx of capital in the form of a new transit station can be accompanied by a sense of distrust that the investment is not for current residents, but for newcomers. Based on the empirical evidence thus far, transit alone is unlikely to dramatically transform a neighborhood, but in locations where gentrification pressure is already strong - in growing cities and in neighborhoods close to other urban amenities, the additional investment in transit may accelerate this pressure. In these neighborhoods, cities need to have a plan for helping residents stay in their homes and to maintain their sense of community. In other places where disinvestment remains except for a new station, sudden change 
Preprint of the publication Delmelle, E.C. (2021). Transit-Induced Gentrification and

Displacement: The State of the Debate. In R. H. M. Pereira \& G. Boisjoly (Editors), Social Issues in Transport Planning (Advances in Transport Policy and Planning Vol. 8). Elsevier. https://doi.org/10.1016/bs.atpp.2021.06.005

is unlikely, but in those places, plans for the station need to take residents' needs seriously and include their voices in the planning process. Forcing a particular type of station or style of development that does not have the buy-in of residents is not going to help ameliorate years of distrust between the planners and marginalized communities (Danley \& Weaver, 2018). This needs to be more than an 'empty ritual' of public participation in the planning process, but one that prioritizes the needs and interests of the community (Silverman et al., 2020). 
Preprint of the publication Delmelle, E.C. (2021). Transit-Induced Gentrification and

Displacement: The State of the Debate. In R. H. M. Pereira \& G. Boisjoly (Editors), Social Issues in Transport Planning (Advances in Transport Policy and Planning Vol. 8). Elsevier. https://doi.org/10.1016/bs.atpp.2021.06.005

\section{References}

Alonso, W. (1964). Location and land use. Toward a general theory of land rent. Location and land use. Toward a general theory of land rent.

Andersson, F., Haltiwanger, J. C., Kutzbach, M. J., Pollakowski, H. O., \& Weinberg, D. H. (2017). Job Displacement and the Duration of Joblessness: The Role of Spatial Mismatch. The Review of Economics and Statistics, 100(2), 203-218.

Atkinson-Palombo, C. (2010). Comparing the capitalisation benefits of light-rail transit and overlay zoning for single-family houses and condos by neighbourhood type in metropolitan Phoenix, Arizona. Urban Studies, 47(11), 2409-2426.

Baker, D. M., \& Lee, B. (2019). How does light rail transit (LRT) impact gentrification? Evidence from fourteen US urbanized areas. Journal of Planning Education and Research, 39(1), 35-49.

Bardaka, E., Delgado, M. S., \& Florax, R. J. (2018). Causal identification of transit-induced gentrification and spatial spillover effects: The case of the Denver light rail. Journal of Transport Geography, 71, 15-31.

Bartholomew, K., \& Ewing, R. (2011). Hedonic price effects of pedestrian-and transit-oriented development. Journal of Planning Literature, 26(1), 18-34.

Barton, M. S., \& Gibbons, J. (2017). A stop too far: How does public transportation concentration influence neighbourhood median household income? Urban Studies, 54(2), 538-554.

Been, V., Ellen, I. G., \& O'Regan, K. (2019). Supply skepticism: Housing supply and affordability. Housing Policy Debate, 29(1), 25-40.

Bereitschaft, B. (2014). Neighbourhood change among creative-cultural districts in mid-sized US metropolitan areas, 2000-10. Regional Studies, Regional Science, 1(1), 158-183.

Bhattacharjee, S., \& Goetz, A. R. (2016). The rail transit system and land use change in the Denver metro region. Journal of Transport Geography, 54, 440-450.

Billings, S. B. (2011). Estimating the value of a new transit option. Regional science and urban economics, 41(6), 525-536.

Bowes, D. R., \& Ihlanfeldt, K. R. (2001). Identifying the impacts of rail transit stations on residential property values. Journal of Urban Economics, 50(1), 1-25.

Calthorpe, P. (1993). The next American metropolis: Ecology, community, and the American dream: Princeton architectural press.

Cao, X., \& Lou, S. (2018). When and how much did the Green Line LRT increase single-family housing values in St. Paul, Minnesota?. Journal of Planning Education and Research, 38(4), 427-436.

Cao, J., \& Schoner, J. (2013). Transportation Impact of Transitways: A Case Study of Hiawatha Light Rail Transit in Minneapolis.

Carlton, I. (2019). Transit Planners' Transit-Oriented Development-Related Practices and Theories. Journal of Planning Education and Research, 39(4), 508-519.

Cervero, R. (2007). Transit-oriented development's ridership bonus: a product of self-selection and public policies. Environment and Planning A, 39(9), 2068-2085.

Cervero, R., Ferrell, C., \& Murphy, S. (2002). Transit-oriented development and joint development in the United States: A literature review. TCRP research results digest, (52).

Culver, G. (2017). Mobility and the making of the neoliberal "creative city": The streetcar as a creative city project? Journal of Transport Geography, 58, 22-30. 
Preprint of the publication Delmelle, E.C. (2021). Transit-Induced Gentrification and

Displacement: The State of the Debate. In R. H. M. Pereira \& G. Boisjoly (Editors), Social Issues in Transport Planning (Advances in Transport Policy and Planning Vol. 8). Elsevier. https://doi.org/10.1016/bs.atpp.2021.06.005

Danley, S., \& Weaver, R. (2018). "They're not building it for us": displacement pressure, unwelcomeness, and protesting neighborhood investment. Societies, 8(3), 74.

Debrezion, G., Pels, E., \& Rietveld, P. (2007). The impact of railway stations on residential and commercial property value: a meta-analysis. The Journal of Real Estate Finance and Economics, 35(2), 161180.

Deka, D. (2017). Benchmarking gentrification near commuter rail stations in New Jersey. Urban Studies, 54(13), 2955-2972.

Delmelle, E., \& Nilsson, I. (2020). New rail transit stations and the out-migration of low-income residents. Urban Studies, 57(1), 134-151.

Delmelle, E. C. (2016). Mapping the DNA of urban neighborhoods: Clustering longitudinal sequences of neighborhood socioeconomic change. Annals of the American Association of Geographers, 106(1), 36-56.

Delmelle, E. C. (2017). Differentiating pathways of neighborhood change in 50 US metropolitan areas. Environment and Planning A, 49(10), 2402-2424.

Delmelle, E. C., Nilsson, I., \& Bryant, A. (2020). Investigating Transit-Induced Displacement Using Eviction Data. Housing Policy Debate, 1-16.

Delmelle, E. C., Nilsson, I., \& Schuch, J. C. (2020). Who's Moving In? A Longitudinal Analysis of Home Purchase Loan Borrowers in New Transit Neighborhoods. Geographical analysis.

Dong, H. (2017). Rail-transit-induced gentrification and the affordability paradox of TOD. Journal of Transport Geography, 63, 1-10.

Duncan, M. (2011a). The impact of transit-oriented development on housing prices in San Diego, CA. Urban Studies, 48(1), 101-127.

Duncan, M. (2011b). The synergistic influence of light rail stations and zoning on home prices. Environment and Planning A, 43(9), 2125-2142.

Efthymiou, D., \& Antoniou, C. (2013). How do transport infrastructure and policies affect house prices and rents? Evidence from Athens, Greece. Transportation Research Part A: Policy and Practice, 52, 122.

Eliasson, J., Kopsch, F., Mandell, S., \& Wilhelmsson, M. (2020). Transport Mode and the Value of Accessibility-A Potential Input for Sustainable Investment Analysis. Sustainability, 12(5), 2143.

Ferbrache, F., \& Knowles, R. D. (2017). City boosterism and place-making with light rail transit: A critical review of light rail impacts on city image and quality. Geoforum, 80, 103-113.

Golub, A., Guhathakurta, S., \& Sollapuram, B. (2012). Spatial and temporal capitalization effects of light rail in Phoenix: From conception, planning, and construction to operation. Journal of Planning Education and Research, 32(4), 415-429.

Hamidi, S., Kittrell, K., \& Ewing, R. (2016). Value of transit as reflected in US single-family home premiums: A meta-analysis. Transportation Research Record, 2543(1), 108-115.

Heilmann, K. (2018). Transit access and neighborhood segregation. Evidence from the Dallas light rail system. Regional science and urban economics, 73, 237-250.

Hess, C. L. (2018). Light-rail Investment in Seattle: gentrification pressures and trends in neighborhood Ethnoracial composition. Urban Affairs Review, 1078087418758959.

Hess, D. B., \& Almeida, T. M. (2007). Impact of proximity to light rail rapid transit on station-area property values in Buffalo, New York. Urban Studies, 44(5-6), 1041-1068.

Hess, D. B., \& Lombardi, P. A. (2004). Policy support for and barriers to transit-oriented development in the inner city: Literature review. Transportation Research Record, 1887(1), 26-33. 
Preprint of the publication Delmelle, E.C. (2021). Transit-Induced Gentrification and

Displacement: The State of the Debate. In R. H. M. Pereira \& G. Boisjoly (Editors), Social Issues in Transport Planning (Advances in Transport Policy and Planning Vol. 8). Elsevier. https://doi.org/10.1016/bs.atpp.2021.06.005

Higgins, C., \& Kanaroglou, P. (2018). Rapid transit, transit-oriented development, and the contextual sensitivity of land value uplift in Toronto. Urban Studies, 55(10), 2197-2225. doi:10.1177/0042098017712680

Huang, H. (1996). The land-use impacts of urban rail transit systems. Journal of Planning Literature, 11(1), 17-30.

Hyra, D. (2015). The back-to-the-city movement: Neighbourhood redevelopment and processes of political and cultural displacement. Urban Studies, 52(10), 1753-1773.

Jackson, S. L., \& Buckman, J. (2020). Light rail development with or without gentrification?: Neighborhood perspectives on changing sense of place in Denver, Colorado. Journal of Transport Geography, 84, 102678.

Jin, J., \& Paulsen, K. (2018). Does accessibility matter? Understanding the effect of job accessibility on labour market outcomes. Urban Studies, 55(1), 91-115.

Kahn, M. E. (2007). Gentrification trends in new transit-oriented communities: evidence from 14 cities that expanded and built rail transit systems. Real Estate Economics, 35(2), 155-182.

Ke, Y., \& Gkritza, K. (2019). Light rail transit and housing markets in Charlotte-Mecklenburg County, North Carolina: Announcement and operations effects using quasi-experimental methods. Journal of Transport Geography, 76, 212-220.

Liu, X., Deng, Y., \& Le Vine, S. (2016). Residential relocation in response to light rail transit investment: case study of the Hudson-Bergen Light Rail system. Journal of Modern Transportation, 24(2), 139144.

Lund, H. (2006). Reasons for living in a transit-oriented development, and associated transit use. Journal of the American Planning Association, 72(3), 357-366.

Lung-Amam, W., Pendall, R., \& Knaap, E. (2019). Mi casa no es su casa: The fight for Equitable transitoriented development in an inner-ring suburb. Journal of Planning Education and Research, 39(4), 442-455.

Makarewicz, C., Dantzler, P., \& Adkins, A. (2020). Another Look at Location Affordability: Understanding the Detailed Effects of Income and Urban Form on Housing and Transportation Expenditures. Housing Policy Debate, 1-23.

Marcuse, P. (1985). Gentrification, abandonment, and displacement: Connections, causes, and policy responses in New York City. Wash. UJ Urb. \& Contemp. L., 28, 195.

Mathur, S. (2020). Impact of transit stations on house prices across entire price spectrum: A quantile regression approach. Land Use Policy, 99, 104828.

Muth, R. F. (1969). CITIES AND HOUSING; THE SPATIAL PATTERN OF URBAN RESIDENTIAL LAND USE.

Newman, K., \& Wyly, E. K. (2006). The right to stay put, revisited: Gentrification and resistance to displacement in New York City. Urban Studies, 43(1), 23-57.

Nilsson, I., \& Delmelle, E. (2018). Transit investments and neighborhood change: On the likelihood of change. Journal of Transport Geography, 66, 167-179.

Nilsson, I., \& Delmelle, E. C. (2020). Impact of new rail transit stations on neighborhood destination choices and income segregation. Cities, 102, 102737.

Nilsson, I., Schuch, J. C., Delmelle, E. C., \& Canales, K. L. (2020). Should I stay or should I go? A survey analysis of neighborhood change and residential mobility concerns around new light rail stations in Charlotte, NC. Journal of Transport Geography, 86, 102790. 
Preprint of the publication Delmelle, E.C. (2021). Transit-Induced Gentrification and

Displacement: The State of the Debate. In R. H. M. Pereira \& G. Boisjoly (Editors), Social Issues in Transport Planning (Advances in Transport Policy and Planning Vol. 8). Elsevier. https://doi.org/10.1016/bs.atpp.2021.06.005

Padeiro, M., Louro, A., \& da Costa, N. M. (2019). Transit-oriented development and gentrification: A systematic review. Transport Reviews, 39(6), 733-754.

Pilgram, C. A., \& West, S. E. (2018). Fading premiums: The effect of light rail on residential property values in Minneapolis, Minnesota. Regional science and urban economics, 69, 1-10.

Pollack, S., Bluestone, B., \& Billingham, C. (2010). Maintaining diversity in America's transit-rich neighborhoods: Tools for equitable neighborhood change.

Rayle, L. (2015). Investigating the connection between transit-oriented development and displacement: Four hypotheses. Housing Policy Debate, 25(3), 531-548.

Redfearn, C. L. (2009). How informative are average effects? Hedonic regression and amenity capitalization in complex urban housing markets. Regional science and urban economics, 39(3), 297-306.

Renne, J. L., Tolford, T., Hamidi, S., \& Ewing, R. (2016). The cost and affordability paradox of transitoriented development: A comparison of housing and transportation costs across transit-oriented development, hybrid and transit-adjacent development station typologies. Housing Policy Debate, 26(4-5), 819-834.

Rérat, P. (2018). Spatial capital and planetary gentrification: residential location, mobility and social inequalities Handbook of Gentrification Studies: Edward Elgar Publishing.

Revington, N. (2015). Gentrification, transit, and land use: Moving beyond neoclassical theory. Geography Compass, 9(3), 152-163.

Rodnyansky, S. (2018). Household Mobility and Neighborhood Impacts. University of Southern California.

Rosenthal, T. J. (2018). Transit-Oriented development? More like transit rider displacement. Los Angeles Times. Retrieved from https://www.latimes.com/opinion/op-ed/la-oe-rosenthal-transitgentrification-metro-ridership-20180220-story.html

Silverman, R. M., Taylor Jr, H. L., Yin, L., Miller, C., \& Buggs, P. (2020). Are we still going through the empty ritual of participation? Inner-city residents' and other grassroots stakeholders' perceptions of public input and neighborhood revitalization. Critical Sociology, 46(3), 413-428.

Smart, M. J., \& Klein, N. J. (2018). Complicating the story of location affordability. Housing Policy Debate, 28(3), 393-410.

Tiebout, C. M. (1956). A pure theory of local expenditures. Journal of political economy, 64(5), 416-424.

Wagner, G. A., Komarek, T., \& Martin, J. (2017). Is the light rail "Tide" lifting property values? Evidence from Hampton Roads, VA. Regional science and urban economics, 65, 25-37.

Zhong, H., \& Li, W. (2016). Rail transit investment and property values: An old tale retold. Transport Policy, $51,33-48$. 